\title{
Replacement therapy in the mucopolysaccharidoses
}

\author{
MICHAEL F. DEAN \\ From the Division of Biochemistry, Kennedy Institute of Rheumatology, London
}

Glycosaminoglycans (GAG), one of the major constituents of connective tissues, are long, unbranched polysaccharides that can contain as many as 100 sugar residues per chain (Muir and Hardingham, 1975). They are normally present not as free chains but grouped together in large numbers with each chain covalently linked at one end (the reducing terminus) to a central protein core, the whole forming a single proteoglycan molecule. Each GAG chain is composed of alternating residues of uronic acid and hexosamine, except for an atypical trisaccharide linkage region at the reducing terminus. In keratan sulphate, however, uronic acid is replaced by galactose. The hexosamine residues (D-glucosamine or D-galactosamine) are usually- $\mathrm{N}$-acetylated and $\mathrm{O}$ sulphated, but $\mathrm{N}$-sulphate groups are often present in heparin and heparan sulphate. The uronic acid residues are either D-glucuronic or L-iduronic, with the latter often being sulphated.

Catabolism of GAG is a complicated process. Complete chains can be degraded into smaller fragments by the action of endoglycosidases acting on susceptible internal linkages such as, for example, testicular hyaluronidase (EC 3.2.1.35), which can degrade chondroitin sulphates and hyaluronic acid to produce tetra- and hexasaccharides and has a similar but more limited action on dermatan sulphate. Similarly, an endoglycosidase found in human platelets (Wasteson et al., 1970) can degrade heparan sulphate to produce a range of GAG fragments, the smallest equivalent in size to a hexasaccharide. Complete catabolism to release constituent monosaccharides and inorganic sulphate then requires the concerted action of a number of different lysosomal exoglycosidase and sulphatase enzymes that remove one sugar residue or sulphate group at a time from the non-reducing terminal end of the remaining partially degraded GAG chains. A deficiency in any one of these enzymes interrupts the sequence, leading to intracellular accumulation of partially degraded GAG as lysosomal storage products and their excretion in large amounts in urine. To date seven such enzyme deficiencies have been described (Table 1). They give rise to the group of irherited diseases of connective tissue known as the mucopolysaccharidoses.

\section{Cultured fibroblasts and corrective factors}

The discovery of the nature of the defect in each type of mucopolysaccharidosis arose mainly from the work of Neufeld and her collaborators (Fratantoni et al., 1968, 1969), who showed that when skin fibroblasts from different types of mucopolysaccharidosis were grown together in culture they were able to correct abnormal accumulation of GAG (measured as precipitable ${ }^{35} \mathrm{SO}_{4}$ ) in each others' cells. They further demonstrated that this correction could be achieved simply by adding medium in which cells of a different genotype had been cultured previously, due to the release of soluble 'corrective factors'. These 'corrective factors' were subsequently identified as lysosomal enzymes (Bach et al., 1972; Bach et al., 1973; Kresse, 1973; O’Brien, 1972; Hall et al., 1973; Matalon et al., 1974; Fluharty et al., 1974; GniotSzulzycka and Donnelly, 1976; Singh et al., 1976). Because normal fibroblasts produce all these lysosomal enzymes they are able to correct every type of mucopolysaccharidosis. They are released into the extracellular environment from whence they are taken up by active endocytosis into pinocytotic vesicles (von Figura and Kresse, 1974; Brot et al., 1974; Hickman et al., 1974) which can then fuse with lysosomes containing partially degraded GAG. Lysosomal deficiency diseases like the mucopolysaccharidoses are thus ideally suited to replacement therapy with an external source of active enzymes.

\section{Replacement therapy by plasma infusion}

The discovery that the mucopolysaccharidoses were a related group of lysosomal enzyme deficiency diseases prompted a number of attemptsat replacement therapy, with normal plasma as the most readily available source of active enzymes. The first attempt was made by Di Ferrante et al. (1971), who infused about 11 of plasma into one child with Hurler's disease and two with Hunter's disease. This was followed by a transfusion of leucocytes suspended in a small volume of autologous plasma into another patient with Hunter's disease (Knudson et al., 1971). These transfusions induced increased breakdown and excretion of dermatan and heparan sulphates, while 
Table 1 Classification of mucopolysaccharidoses

\begin{tabular}{lll}
\hline Disease & Deficient enzyme & Storage product \\
\hline Hurler/Scheie diseases & a-L-Iduronidase & Dermatan, heparan sulphates \\
Hunter's disease & a-L-Idurono-2-sulphate sulphatase & Dermatan, heparan sulphates \\
Sanfilippo A disease & Heparan-N-sulphatase & Heparan sulphate \\
Sanfilippo B disease & N-Acetyl-a-glucosaminidase & Heparan sulphate \\
Morquio's disease & N-Acetylgalactosamine-6-sulphate sulphatase & Keratan sulphate and chondroitin-6-sulphate \\
Maroteaux-Lamy disease & N-Acetylgalactosamine-4-sulphate sulphatase & Dermatan sulphate \\
B-Glucuronidase deficiency & (aryl suphatase B) & Dermatan, heparan sulphates \\
\hline
\end{tabular}

clinical changes included a reduction in hyperactivity, an improvement in the patients' poorly vascularised extremities, and improved joint mobility. Normal plasma equivalent to 3.51 of blood was infused into three patients with Sanfilippo's disease by Dean et al. (1973) and one with Hunter's disease (Dean et al., 1975a). The changes seen in these cases after infusion included an increased excretion of uronic acid (see Fig. 1) and an increase in the relative proportions of lower molecular weight oligosaccharides separated by chromatography on Sephadex G-25 (Fig. 2).

These changes were consistent with those expected from increased breakdown and mobilisation of excreted GAG and were not seen when one of the patients with Sanfilippo's disease was infused with an equivalent volume of iso-osmotic dextran solution one year later (Dean et al., 1975b), indicating that the increased output of degraded GAG was a specific phenomenon, attributable to lysosomal enzymes in plasma. Yatziv et al. (1975) also noted transient increases in urinary oligosaccharides derived from heparan sulphate after giving fresh plasma to two siblings with Hunter's disease. Accompanying clinical changes included a decrease in the size of liver and spleen, improved joint mobility, accelerated growth, and a decrease in the incidence of respiratory infections.

In contrast, Dekaban et al. (1972) found that infusions of plasma or whole blood had little effect on patients with Hurler's, Hunter's, and Sanfilippo's diseases, while Moser et al. (1974) found that infusions of HLA-compatible leucocytes in Sanfilippo type B disease produced only a transient increase in GAG catabolism. Undoubtedly the differing degrees of response to this form of enzyme replacement therapy were due in part to differences in activity of the enzyme administered, while the transitory nature of the improvements observed is not surprising in view of the short intracellular half lives of many lysosomal glycosidases and sulphatases (Porter et al., 1971; Hickman and Neufeld, 1972; O'Brien et al., 1973; von Figura and Kresse, 1974). Frequent infusions are therefore required to maintain high levels of enzyme activity and long-term replacement therapy by this method is impracticable.

\section{Fibroblasts in replacement therapy}

The in-vitro studies of Neufeld's group established that normal skin fibroblasts release lysosomal enzymes. which can then be taken up by deficient fibroblasts and restore their capacity to degrade GAG (Fratantoni et al., 1968, 1969; Hickman et al., 1974). When circulating enzyme concentrations are raised by infusions of plasma transient increases in catabolism and excretion of stored GAG ensue (Di Ferrante et al., 1971; Dean et al., 1973, 1975a;

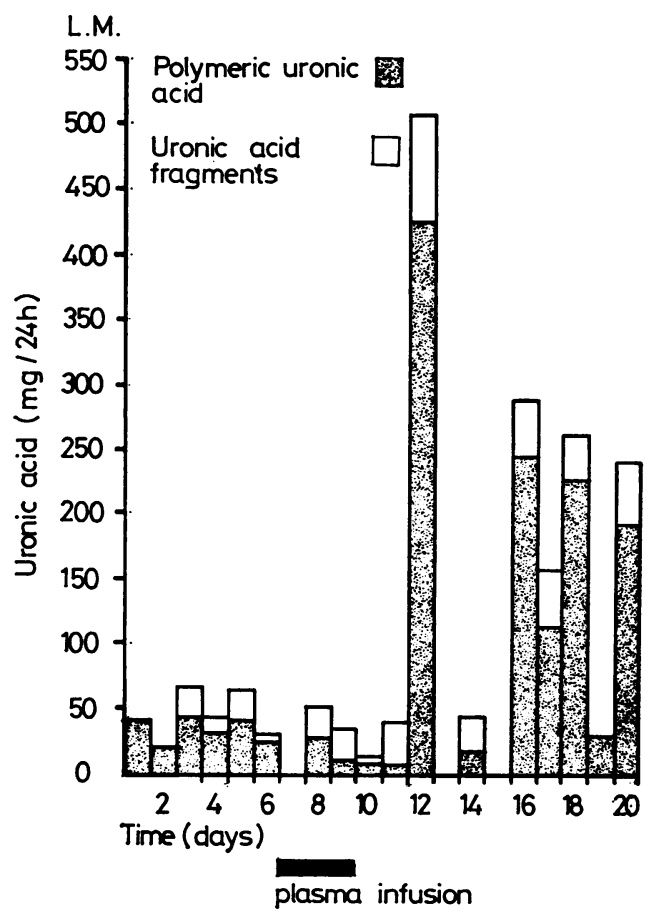

Fig. 1 Effect of plasma infusion on total 24-h excretion of uronic acid in patient with Sanfilippo's disease. Stippled area represents $G A G$ precipitated by 5-aminoacridine, open areas represent uronic acid containing oligosaccharides of lower molecular weight, and dark horizontal bar indicates days on which plasma was given. (Dean et al., 1973). 


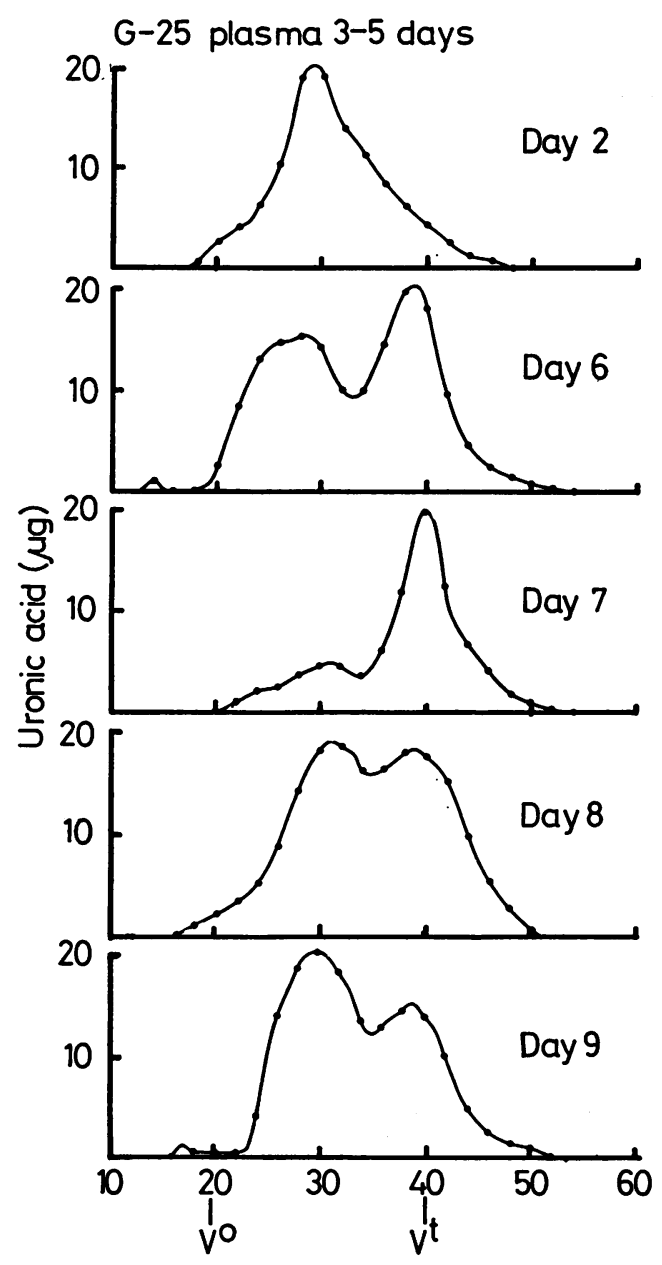

Fraction number

Fig. 2 Effect of plasma infusion on size distribution of oligosaccharides separated from urine of patient with Sanfilippo's disease by gel filtration on Sephadex G-25. (Dean et al., 1973).

Yatziv et al., 1975). Amalgamation of these two sets of data suggests that skin fibroblasts themselves might provide a more continuous source of lysosomal enzymes in vivo and thus increase the rate of catabolism of accumulated GAG 'over an extended period of time.

This possibility was examined by Dean et al. (1975c), who supplied fibroblasts as a skin allograft in a boy with Hunter's disease and noted a significant increase in excretion of uronic acid, particularly oligosaccharides of lower molecular weight, after grafting. When these oligosaccharides were fraction- ated by chromatography on Sephadex G-25 the relative proportions of oligosaccharides of lowest molecular weight increased (Fig. 3), while at the same time the sulphate/hexuronic acid molar ratio of the highest molecular weight fraction fell from an abnormally high value of almost $2: 1$ in preimplantation samples to a normal level of $1: 1$ in samples taken after treatment. This increased catabolism and desulphation of accumulated oligosaccharides suggested that the circulating level of $a$-L-idurono-2-sulphate sulphatase (deficient in Hunter's disease) had increased after the grafting. This assumption was confirmed by the increased excretion of 'corrective factor' (which contains $a-\mathrm{L}-$ idurono-2-sulphate sulphatase) in the patient's urine. It rosefrom a level below $1 \mathrm{U} / 24 \mathrm{~h}$ to nearly $4 \mathrm{U} / 24 \mathrm{~h}$, and enzyme output and catabolism of accumulated

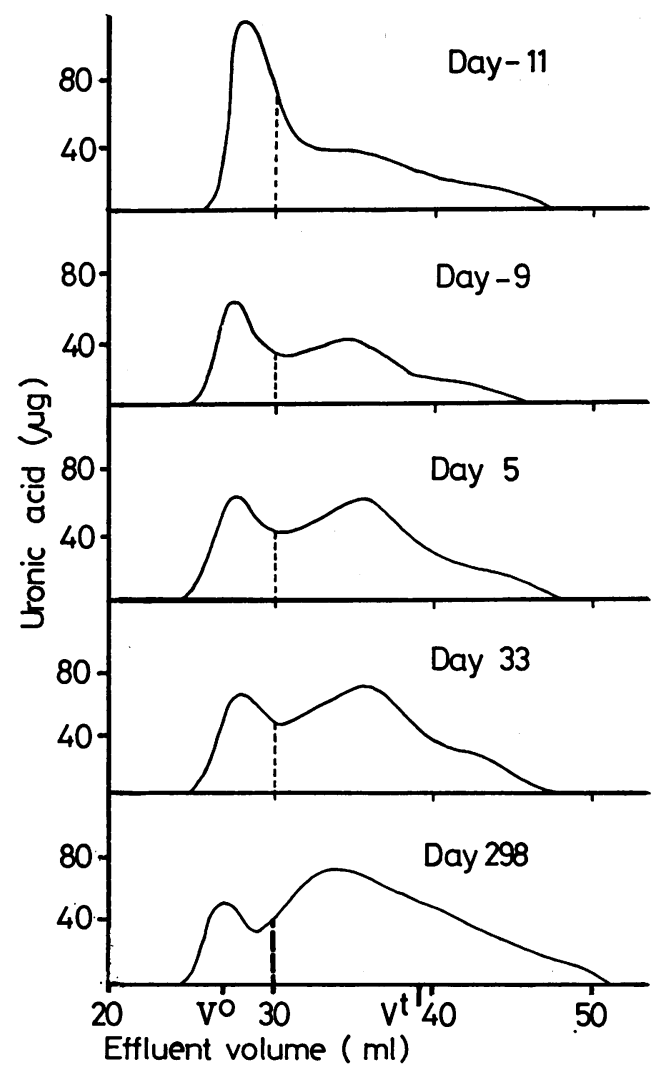

Fig. 3 Effect of skin allografts on size distribution of oligosaccharides separated from urine of a patient with Hunter's disease by gel filtration on Sephadex G-25. Samples taken before grafting designated by negative numbers. (Reproduced from Dean et al. (1975c) by permission of the Editor of Nature (London). 
oligosaccharides were both increased more than nine months after grafting.

\section{Transplantation of histocompatible fibroblasts}

The promising results produced by skin allografts encouraged transplantation of cultured fibroblasts themselves in three further patients with Hunter's disease (for details see Dean et al., 1976; Dean et al., 1978). This simplified procedure does not require surgery or general anaesthesia, merely a subcutaneous injection of a suspension of donor cells. Selection of donor cells which are HLA-compatible with those of the patient minimises the risk of rejection and transplanted cells may thus continue to grow and divide, as when cultured in vitro.

The ability of normal skin fibroblasts to synthesise and release all the lysosomal enzymes required for normal GAG catabolism means that all types of mucopolysaccharidosis can be corrected by this procedure, with no need for prior purification of enzymes. Furthermore, the apparent ability of a relatively small increase in intracellular enzyme levels (of the order of $5 \%$ ) to induce a high degree of correction of GAG catabolism (Bach et al., 1972; O'Brien et al., 1973) suggests that a relatively small number of cells can have a disproportionately large effect.

The effectiveness of fibroblast transplantation was assessed by analysis of urinary GAG and oligosaccharides to determine the effect of donor cells on the rate of catabolism of accumulated dermatan and heparan sulphates. In addition, the appearance of Hunter corrective factor in urine was measured by the method of Cantz et al. (1972) and $\alpha$-L-idurono2-sulphate sulphatase activity measured directly in serum and leucocytes using an $\left[{ }^{3} \mathrm{H}\right]$-labelled disulphated disaccharide as a substrate (Lim et al., 1974). During this measurement of enzyme activity radioactive monosulphated reaction products were separated from the remaining disulphated substrate by ion-exchange chromatography on columns of ECTEOLA cellulose (Liebaers and Neufeld, 1976).

\section{CHANGES IN EXCRETED GAG AFTER \\ TRANSPLANTATION}

There was an immediate increase in total uronic acid excreted by each patient after transplantation, mainly in the form of oligosaccharides of low molecular weight, as would be expected from an increased rate of catabolism of accumulated GAG. Fig. 4 shows data for one of the patients who received fibroblasts (case 1). In addition to the increased excretion of oligosaccharides there was also a small increase in output of GAG. The reason for this is not yet clear.
The Bio-Gel P-2 elution profiles of uronic acidcontaining oligosaccharides separated from patients' urine before transplantation were compared with those obtained from normal children. Although four fractions were resolved from both normal and pathological samples the relative proportions were different, with pathological urines containing considerably more of the larger oligosaccharides (Components I and II, Fig. 5) as well as of the unresolved fraction eluted with the void volume. In samples taken after transplantation the relative proportions of components I and II decreased so that

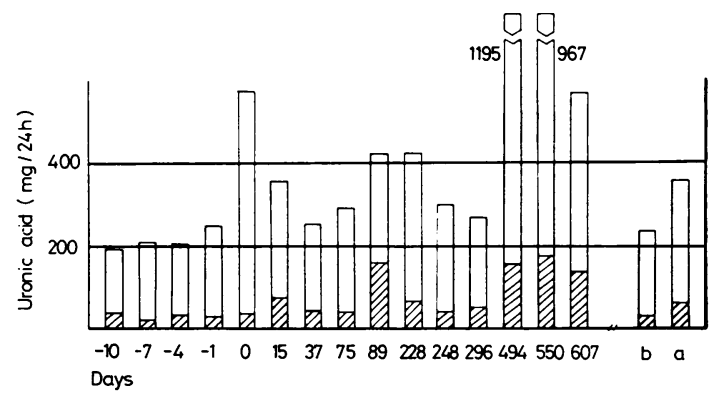

Fig. 4 Effect of transplanted fibroblasts on total 24-h excretion of uronic acid in patient (case 1) with Hunter's disease. Cross-hatched areas represent $G A G$ precipitated by 5-aminoacridine, open areas uronic acid containing oligosaccharides of lower molecular weight. Samples taken before transplantation designated by negative numbers.

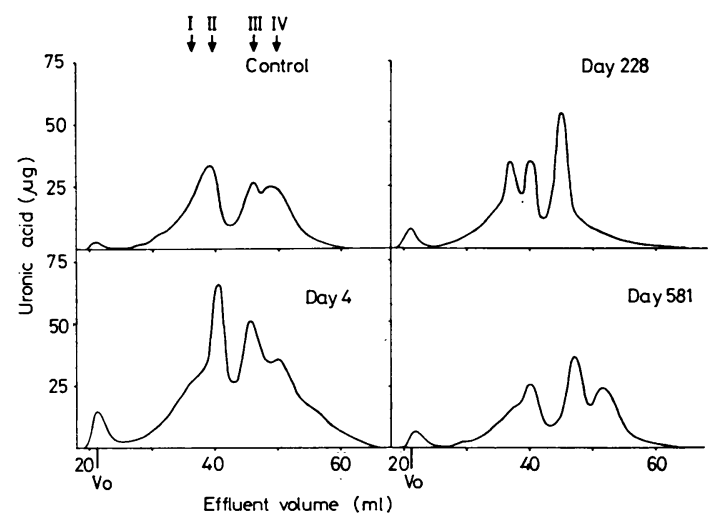

Fig. 5 Elution profiles of uronic acid-containing oligosaccharides separated from urine of patient (case 1) with Hunter's disease by chromatography on Bio-Gel $P$-2. A profile from a sample taken before transplantation (day 4) and from early and late posttransplantation samples is shown together with that of a normal age matched control sample for comparison. (Reproduced from Dean et al. (1978) by permission of the publishers). 
the elution profiles changed to resemble closely those of normal urine (Fig. 5). These changes were again consistent with those expected from increased catabolism of oligosaccharides.

Since the pronounced deficiency of $\alpha$-L-idurono-2sulphate sulphatase in Hunter's disease leads to a break in catabolism of dermatan and heparan sulphates, leaving a sulphated iduronic acid residue at the non-reducing terminus of accumulated GAG and oligosaccharides, the sulphate:uronic acid molar ratios of the oligosaccharide component I separated by chromatography on Bio-Gel P-2 were determined. Values were abnormally high in all three patients before transplantation, ranging from $1 \cdot 6: 1$ to $2 \cdot 0: 1$, compared with the normal value of 1.0:1 (see Table 2). After transplantation the sulphate:hexuronic acid ratios decreased to a level at or a little below that of age-matched control samples and remained low throughout the period monitored. In addition to the decrease in sulphate content of fraction I the iduronic acid content of the monosaccharide fraction (fraction IV) estimated by glc was found to be considerably higher in pooled samples analysed after transplantation than in those sampled before treatment (see Table 3). Both of these observations strongly suggest an increase in $\alpha$-L-idurono-2-sulphate sulphatase activity subsequent to transplantation, with the removal of sulphate groups from non-reducing terminal iduronic acid groups allowing them in turn to be removed by $a$-L-iduronidase, which is not normally deficient in Hunter's disease.

\section{CHANGES IN ACTIVITY OF IDURONATE}

\section{SULPHATASE}

Protein concentrates prepared from patients' urine by precipitation with ammonium sulphate (Dean et al., 1975c) were tested for the presence of Hunter 'corrective factor' (which contains $a$-L-idurono-2sulphate sulphatase) by their ability to correct abnormal ${ }^{35}$ S-sulphate incorporation by the patients' own fibroblasts (Cantz et al., 1972). Samples of urine collected before transplantation were almost totally devoid of activity, with mean values $<0.5 \mathrm{U} / 24 \mathrm{~h}$ (Fig. 6). In contrast, samples collected after transplantation were much more active, with mean values ranging from about $3 \mathrm{U} / 24 \mathrm{~h}$ to more than $11 \mathrm{U} / 24 \mathrm{~h}$ for each patient (Table 4), although there was considerable daily fluctuation in output of 'corrective factor'. The results of direct measurement of $\alpha$-Lidurono-2-sulphate sulphatase activity in serum and leucocytes of both patients and untreated cases of Hunter's disease are given in Table 5. Twice as much substrate was hydrolysed in $24 \mathrm{~h}$ by sera from transplanted patients than from untreated control cases when expressed as $\mathrm{DPM} / \mathrm{mg}$ serum protein
Table 2 Sulphate/uronic acid molar ratios of oligosaccharide component I separated on Bio-Gel P-2. Group A samples were collected 0-3 months before transplantation, group B samples from 1 week to 6 months after transplantation, and group $C$ samples from 6 months to 2 years after transplantation. Each group was rechromatographed on Bio-Gel P-2. Sodium ions, which interfere with $\mathrm{SO}_{4}$ determination, were removed on a column of Dowex-50 ( $\mathrm{H}^{+}$form $)$before analysis. Number of samples pooled in each group given in parentheses (from Dean et al., 1978, by permission of the publishers)

\begin{tabular}{llll}
\hline Case No. & Group A & Group B & Group C \\
\hline 1 & $2 \cdot 10(3)$ & $1.15(5)$ & $1.25(7)$ \\
2 & $2 \cdot 14(3)$ & $0.54(7)$ & $0.87(2)$ \\
3 & $1.60(6)$ & $0.95(7)$ & $0.93(4)$ \\
Control & 1.02 & - & - \\
\hline
\end{tabular}

Table 3 Effect of fibroblast transplantation on proportion of iduronic acid in monosaccharide fraction eluted from Bio-Gel P-2. Iduronic acid content of monosaccharide expressed as percentage of total uronic acid. Group A samples were collected 0-6 weeks before transplantation, group $B$ samples 0-3 months after transplantation, and group C samples 6-16 months after transplantation. Number of samples pooled in each group given in parentheses. Relative amounts of glucuronic and iduronic acids in each group were determined by glc after conversion to trimethylsilyl derivatives, and iduronic acid expressed as a percentage of the total hexuronic acid

\begin{tabular}{lll}
\hline Group A & Group B & Group C \\
\hline $31.9(5)$ & $45 \cdot 7(6)$ & $57 \cdot 3(6)$ \\
\hline
\end{tabular}

and the leucocyte homogenate had 10 times the activity of an untreated control.

\section{Discussion}

Transplantation of histocompatible normal fibroblasts increased the activity of $a$-L-idurono-2sulphate sulphatase when measured in the urine of all three transplanted patients as corrective factor. This increase in activity was unaffected either by decreasing dosage or total withdrawal of the immunosuppressive drugs given to decrease the risk of rejection. The raised enzyme levels found by direct measurement in the serum and leucocytes of the treated patients were present in blood samples collected at least one year after the end of immunosuppressive therapy and between 1.5 and 3 years after transplantation.

These raised levels of activity seemed to be enough to induce catabolism of a significant proportion of the accumulated dermatan and heparan sulphates, since quantitative analysis showed that excretion of 


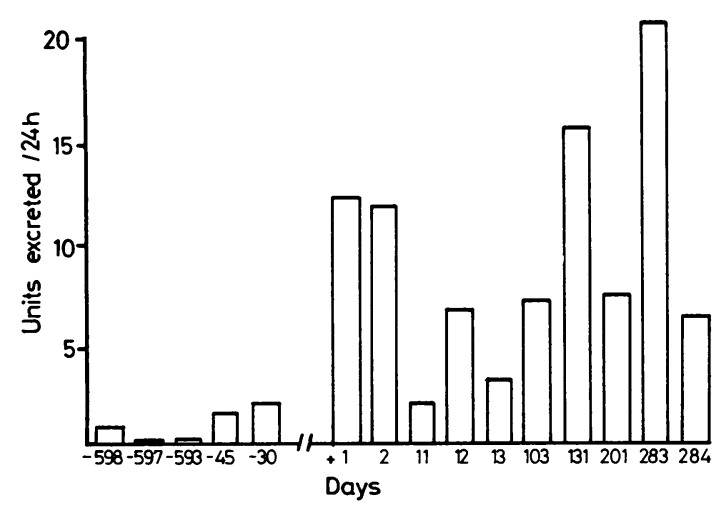

Fig. 6 Effect of transplanted fibroblasts on total 24-h output of 'corrective factor' isolated from urine of patient with Hunter's disease by precipitation with ammonium sulphate. Samples taken before transplantation designated by negative numbers. (Reproduced from Dean et al., 1978 by permission of the publishers).

these GAG, and particularly of the oligosaccharides derived from them, increased after treatment. The abnormal molecular size distribution of oligosaccharides separated by chromatography on Bio-Gel P-2 before treatment changed to a more normal size distribution, the sulphate:uronic acid ratio of oversulphated fractions fell to normal values, and the iduronic acid content of the monosaccharide fraction

Table 4 Mean 24-hour excretion of Hunter corrective factor before and after transplantation. Values represent mean units of correction (as defined by Barton and Neufeld, 1971) $\pm S E$ from all samples analysed. Numbers of analyses in parentheses (from Dean et al., 1978 , by permission of the publishers)

\begin{tabular}{llll}
\hline Case No. & Before & After & Control \\
\hline 1 & $0.47 \pm 0.14(9)$ & $3.0 \pm 0.47(15)$ & $45.1(4)$ \\
2 & $0.45 \pm 0.2(5)$ & $5.8 \pm 1.5(17)$ & $49.0(4)$ \\
3 & $0.45 \pm 0.2(5)$ & $11.3 \pm 5.1(14)$ & $59.8(3)$ \\
\hline
\end{tabular}

rose after transplantation. All these changes persisted after the end of immunosuppressive therapy and were again consistent with those expected from increased catabolism of accumulated oligosaccharides.

Both host and donor cells were fully HLA compatible and gave no mixed leucocyte reaction. Because of this the transplanted cells were probably not rejected and continued to produce lysosomal enzymes, including $\alpha$-L-idurono-2-sulphate sulphatase, which could then be endocytosed into the lysosomes of host cells. The ability of the respective donor fibroblasts to correct abnormal ${ }^{35} \mathrm{SO}_{4}$ metabolism in each of the patient's cells in vitro (Dean et al., 1976, 1978) had been shown before transplantation. Probably this ability may persist after transplantation, since active endocytosis of the appropriate lysosomal enzymes in vitro has been shown by fibroblasts cultured from patients with Sanfilippo's disease and $\beta$-glucuronidase deficiency (O'Brien et al., 1973; von Figura and Kresse, 1974; Kaplan et al., 1977). Transfer of lysosomal enzymes from normal donor cells to deficient recipient cells is also known to take place in vivo. For example, lymphocytes from a natural chimeric male calf deficient in $a$-mannosidase took up $a$-mannosidase from the blood cells of its normal female co-twin at an early stage of fetal development (Jolly et al., 1976). Similarly, $\beta$-glucuronidase can be transferred from normal to deficient cells in mosaic tissues of tetraparental mice (Feder, 1976), while heterozygous females with Hunter's disease have two populations of cells, one of which is as deficient in $a$-L-idurono2-sulphate sulphatase as cells from affected patients (Migeon et al., 1977). These heterozygotes do not show symptoms of Hunter's disease, suggesting that transfer of enzymes from normal cells to abnormal ones is a normal event in vivo. Nevertheless, the results we observed in vivo may possibly have been due to a factor released by donor cells that can stimulate host cells themselves to produce a small amount of normal enzyme.

Table 5 Activity of a-L-idurono-2-sulphate sulphatase in sera and leucocytes of treated Hunter patients who received fibroblast transplants compared with untreated Hunter patients as controls (from Dean et al., 1978, by permission of the publishers)

\begin{tabular}{|c|c|c|c|c|c|c|c|}
\hline \multirow[t]{2}{*}{ Case No. } & \multicolumn{2}{|c|}{ Control Hunter sera } & \multirow{2}{*}{$\begin{array}{l}\text { Control Hunter } \\
\text { leucocyte } \\
\text { activity } \\
\text { (DPM/mg } \\
\text { protein) }\end{array}$} & \multicolumn{3}{|c|}{ Treated Hunter sera } & \multirow{2}{*}{$\begin{array}{l}\text { Treated Hunter } \\
\text { leucocyte } \\
\text { activity } \\
\text { (DPM/mg } \\
\text { protein) }\end{array}$} \\
\hline & $\begin{array}{l}\text { Activity } \\
\text { (DPM/mg } \\
\text { protein) }\end{array}$ & $\begin{array}{c}\text { Mean } \\
\text { activity } \\
\pm S E\end{array}$ & & Case No. & $\begin{array}{l}\text { Activity } \\
\text { (DPM/mg } \\
\text { protein) }\end{array}$ & $\begin{array}{l}\text { Mean } \\
\text { activity } \\
\pm S E\end{array}$ & \\
\hline $\begin{array}{l}4 \\
5 \\
6 \\
7\end{array}$ & $\begin{array}{l}2763 \\
1695 \\
1408 \\
1706\end{array}$ & $\begin{array}{l}\overline{1893} \pm 298 * \\
-\end{array}$ & $\begin{array}{l}3906 \\
- \\
-\end{array}$ & $\begin{array}{l}1 \\
2 \\
3\end{array}$ & $\begin{array}{l}3420 \\
3029 \\
3505\end{array}$ & $\overline{3318} \pm 147^{*}$ & $\begin{array}{l}30768 \\
- \\
-\end{array}$ \\
\hline
\end{tabular}

Final substrate concentration was $2.0 \mathrm{mmol}$.

*P > 0.01, Student's $t$ test. 
The fact that withdrawal of immunosuppressive drugs did not produce a corresponding decrease in $\alpha$-L-idurono-2-sulphate sulphatase activity or GAG catabolism suggests that when a good histcompatibility match has been achieved it may not be necessary to suppress the immune response when fibroblasts are transplanted. We do not know how long donor fibroblasts can survive in the host, or indeed whether they can survive, but the presence of increased enzyme activity more than three years after transplantation suggests they can survive for at least this length of time.

The optimum number of cells that should be transplanted is as yet unclear, although in-vitro studies suggest that a relatively small number can have a large effect. For example, O'Brien et al. (1973) showed that as little as $5 \%$ of normal intracellular levels of $a$ - $\mathrm{N}$-acetylglucosaminidase can induce almost $70 \%$ correction of abnormal ${ }^{35} \mathrm{~S}$-sulphate incorporation in cultured fibroblasts from patients with Sanfilippo type B disease, while Kihara et al. (1973) calculated that only $2-5 \%$ of normal intracellular levels of arylsuphatase restores normal catabolic function in cells from cases of metachromatic leucodystrophy.

Transplantation of fibroblasts has other important advantages in addition to the long-lived nature of the response. Normal fibroblasts contain all the lysosomal sulphatases and exoglycosidases known to be deficient in each type of mucopolysaccharidosis, and conditioned medium in which normal fibroblasts have been cultured can induce normal catabolism of GAG in each of these types. Probably a similar mechanism can operate in vivo, so that all types of mucopolysaccharidosis can be treated by fibroblast transplantation without prior purification of the necessary deficient enzymes. Moreover, since normal fibroblasts can correct abnormal catabolism in cells derived from patients with lysosomal enzyme deficiencies other than the mucopolysaccharidosesfor example, metachromatic leukodystrophy (Kihara et al., 1973) or a-mannosidosis (Mersmann et al., 1976) - transplantation of normal fibroblasts may be of value in treating a wide range of other deficiency diseases.

\section{References}

Bach, G., Eisenberg, F., Jr., Cantz, M., and Neufeld, E. F. (1973). The defect in the Hunter syndrome: deficiency of sulfoiduronate sulfatase. Proceedings of the National Academy of Sciences of the United States of America, 70, 2134-2138.

Bach, G., Friedman, R., Weissmann, B., and Neufeld, E. F. (1972). The defect in Hurler and Scheie Syndromes: Deficiency of $\alpha$-L-iduronidase. Proceedings of the National Academy of Sciences of the United States of America, 69, 2084-2051.

Brot, F. E., Glaser, J. H., Roozen, K. J., Sly, W. S., and Stahl, P. D. (1974). In-vitro correction of deficient human fibroblasts by $\beta$-glucuronidase from different human sources. Biochemical and Biophysical Research Communications, 57, 1-8.

Cantz, M., Chrambach, A., Bach, G., and Neufeld, E. F. (1972). The Hunter corrective factor: purification and preliminary characterisation. Journal of Biological Chemistry, 247, 5456-5462.

Dean, M. F., Benson, P. F., and Muir, H. (1973). Mobilisation of glycosaminoglycans by plasma infusion in Mucopolysaccharidoses Type III: two types of response. Nature New Biology, 243, 143-146.

Dean, M. F., Benson, P. F., and Muir, H. (1975a). Differing patterns of glycosaminoglycan mobilisation in Sanfilippo (MPS III) and Hunter (MPS II) syndromes following infusion of normal plasma. Proceedings of the Third Congress of the International Association for the Scientific Study of Mental Deficiency, edited by D. A. Primose, pp. 270-275. International Association for the Scientific Study of Mental Deficiency, The Hague.

Dean, M. F., Benson, P. F., and Muir, H. (1975b). The effect of dextran infusions on glycosaminoglycan excretion in the Sanfilippo syndrome. Developmental Medicine and Child Neurology, 17, 47-57.

Dean, M. F., Muir, H., Benson, P. F., Button, L. R., Batchelor, J. P., and Bewick, M. (1975c). Increased breakdown of glycosaminoglycans and appearance of corrective enzyme after skin transplants in Hunter syndrome. Nature (London), 257, 609-612.

Dean, M. F., Muir, H., Benson, P. F., Button, L. R., Boylston, A., and Mowbray, J. (1976). Enzyme replacement therapy by fibroblast transplantation in a case of Hunter syndrome. Nature (London), 261, 323-325.

Dean, M. F., Stevens, R. L., Muir, H., Benson, P. F., Button, L. R., Anderson, R. L., Boylston, A., and Mowbray, J. (1978). Enzyme replacement therapy by fibroblast transplantation: long-term biochemical study in three cases of Hunter's disease. Journal of Clinical Investigation, in press.

Dekaban, A. S., Holden, K. R., and Constantopoulos, G. (1972). Effects of fresh plasma or whole blood transfusions on patients with various types of mucopolysaccharidosis. Pediatrics, 50, 688-692.

Di Ferrante, N., Nichols, B., Donnelly, P. V., Neri, G., Hrgovcic, R., and Berglund, R. K. (1971). Induced degradation of glycosaminoglycans in Hurler's and Hunter's syndromes by plasma infusion. Proceedings of the National Academy of Sciences of the United States of America, 68, 303-307.

Feder, N. (1976). Solitary cells and enzyme exchange in tetraparental mice. Nature (London), 263, 67-69.

von Figura, K., and Kresse, H. (1974). Quantitative aspects of pinocytosis and the intracellular fate of $N$-acetyl- $\alpha$-D-glucosaminidase in Sanfilippo B fibroblasts. Journal of Clinical Investigation, 53, 85-90.

Fluharty, A. L., Stevens, R. L., Sanders, D. L., and Kihara, H. (1974). Arylsulphatase B deficiency in Maroteaux-Lamy syndrome cultured fibroblasts. Biochemical and Biophysical Research Communications, 59, 455-461.

Fratantoni, J. C., Hall, C. W., and Neufeld, E. F. (1968). Hurler and Hunter syndromes: mutual correction of the defect in cultured fibroblasts. Science, 162, 570-572.

Fratantoni, J. C., Hall, C. W., and Neufeld, E. F. (1969). The defect in Hurler and Hunter syndromes. II. Deficiency of specific factors involved in mucopolysaccharide degradation. Proceedings of the National Acad- 
emy of Sciences of the United States of America, 64, 360-366.

Gniot-Szulzycka, J., and Donnelly, P. V. (1976). Arylsulphatase B (Maroteaux-Lamy Factor): A part of the enzyme system responsible for sulphate release from mucopolyacccharide fragment. FEBS Letters, 65, 63-68.

Hall, C. W., Cantz, M., and Neufeld, E. F. (1973). A $\beta$-glucuronidase deficient mucopolysaccharidosis: studies in cultured fibroblasts. Archives of Biochemistry and Biophysics, 155, 32-38.

Hickman, S., and Neufeld, E. F. (1972). A hypothesis for I-cell disease: defective hydrolases that do not enter lysosomes. Biochemical and Biophysical Research Communications, 49, 992-999.

Hickman, S., Shapiro, L. J., and Neufeld, E. F. (1974). A recognition marker required for uptake of a lysosomal enzyme by cultured fibroblasts. Biochemical and Biophysical Research Communications, 57, 55-61.

Jolly, R. D., Thompson, K. G., Murphy, C. E., Manktelow, B. W., Bruere, A. M., and Winchester, B. G. (1976). Enzyme replacement therapy-an experiment of nature in a chimeric mannosidosis calf. Pediatric Research, 10, 219-224.

Kaplan, A., Achord, D. T., and Sly, W. S. (1977). Phosphohexosyl components of a lysosomal enzyme are recognised by pinocytosis receptors on human fibroblasts. Proceedings of the National Academy of Sciences of the United States of America, 74, 20262030.

Kihara, H., Porter, M., and Fluharty, A. (1973). Enzyme replacement in cultured fibroblasts from metachromatic leukodystrophy. In Birth Defects, Original Article Series, 9, pp. 19-26.

Knudson, A. G., Di Ferrante, N., and Curtis, J. E. (1971). Effect of leucocyte transfusion in a child with type II mucopolysaccharidosis. Proceedings of the National Academy of Sciences of the United States of America, 68, 1738-1741.

Kresse, H. (1973). Mucopolysaccharidosis IIIA (Sanfillipo A disease): Deficiency of a heparin sulfamidase in skin fibroblasts and leucocytes. Biochemical and Biophysical Research Communications, 54, 1111-1118.

Liebaers, I., and Neufeld, E. F. (1976). Iduronate sulphatase activity in serum, lymphocytes and fibroblastssimplified diagnosis of the Hunter syndrome. Pediatric Research, 10, 733-736.

Lim, T. W., Leder, I. G., Bach, G., and Neufeld, E. F. (1974). An assay for iduronate sulfatase. Carbohydrate
Research, 37, 103-109.

Matalon, R., Arbogast, B., Justice, P., Brandt, I. K., and Dorfman, A. (1974). Morquio's syndrome: deficiency of a chondroitin sulfate $\mathrm{N}$-acetylhexosamine sulfate sulfatase. Biochemical and Biophysical Research Communications, 61, 759-765.

Mersmann, G., von Figura, K., and Buddecke, E. (1976). Storage of mannose-containing material in cultured human mannosidosis cells and metabolic correction by pig kidney $\alpha$-mannosidase. Hoppe-Seyler's z. Physiol. Chem.. 357, 641-648.

Migeon, B. R., Sprenkle, J. A., Liebaers, I., Scott, J. F., and Neufeld, E. F. (1977). X-linked Hunter syndrome: the heterozygous phenotype in cell culture. American Journal of Human Genetics, 29, 448-454.

Moser, H. W., O'Brien, J. S., Atkins, L., Fuller, T. C., Kliman, A., Janowska, S., Russell, P. F., Bartsocas, C. S., Cosimi, B., and Dulaney, J. T. (1974). Infusion of normal HLA identical leukocytes in Sanfilippo disease type B. Archives of Neurology, 31, 329-337.

Muir, H., and Hardingham, T. E. (1975). Structure of proteoglycans. In Biochemistry of Carbohydrates, edited by W. J. Whelan, pp. 153-222. Butterworths, London.

O'Brien, J. S. (1972). Sanfilippo syndrome: profound deficiency of $\alpha$-acetylglucosaminidase activity in organs and skin fibrobalsts from type $\mathbf{B}$ patients. Proceedings of the National Academy of Sciences of the United States of America, 69, 1720-1722.

O'Brien, J. S., Miller, A. L., Loverde, A. W., and Veath, M. L. (1973). Sanfilippo disease type B: enzyme replacement and metabolic correction in cultured fibroblasts. Science, 181, 753-755.

Porter, M. T., Fluharty, A. L., and Kihara, H. (1971). Correction of abnormal cerebrosides ulfate metabolism in cultured metachromatic leukodystrophy fibroblasts. Science, 172, 1263-1265.

Singh, J., Di Ferrante, N., Niebes, P., and Tavella, D. (1976). $N$-acetylgalactosamine-6-sulfate in man: absence of the enzyme in Morquio disease. Journal of Clinical Investigation, 57, 1063-1040.

Wasteson, A., Höök, M., and Westermark, B. (1976). Demonstration of a platelet enzyme degrading heparan sulphate. FEBS Letters, 64, 218-221.

Yatziv, S., Statter, M., Abelink, P., Meshulam, M., and Russell, A. (1975). A therapeutic trial of fresh plasma infusions over a period of 22 months in two siblings with Hunter's syndrome. Israel Journal of Medical Sciences, 11, 802-808. 